\title{
A EDUCAÇÃO QUE TEMOS E A QUE A SOCIEDADE PRECISA
}

\author{
Manoel de Jesus Bastos ${ }^{1}$
}

RESUMO: Este trabalho foi desenvolvido com a intenção de apresentar os dois lados da educação brasileira, onde um avança e o outro patina. O seu principal objetivo não é outro senão explicitar a discrepância existente entre a educação que temos e a que a sociedade realmente necessita para o exercício legal de sua cidadania. É notório que as políticas públicas educacionais tenham avançado, quantitativamente, assim como é notório o seu fracasso em termos de qualidade. A sociedade brasileira não pode concordar com uma educação produtora de analfabetos funcionais uma vez que o país apresenta mais de onze milhões de indivíduos, acima de quinze anos, que não conseguem desenvolver as habilidades necessárias previstas nas leis educacionais. A sociedade conclama por uma educação que proporcione luzes do conhecimento e produza seres pensantes, críticos e capazes de contribuir com o desenvolvimento de sua pátria. A desobediência às normativas educacionais têm gerado resultados insatisfatórios e aumentado a inquietez pela busca da qualidade educacional. Utilizou-se uma pesquisa de cunho bibliográfico com abordagem qualitativa e fundamentada em alguns teóricos e algumas fontes oficiais.

Palavras-chave: Cidadania. Educação. Sistema educacional. Sociedade.

ABSTRACT: This work was developed with the intention of presenting both sides of Brazilian education, where one advances and the other skates. Its main objective is none other than to make explicit the existing discrepancy between the education we have and the one that society really needs for the legal exercise of its citizenship. It is notorious that public educational policies have advanced, quantitatively, as well as their failure in terms of quality. Brazilian society cannot agree with an education that produces functional illiterates since the country has more than eleven million individuals, over fifteen years old, who are unable to develop the necessary skills provided for in educational laws. Society calls for an education that provides light of knowledge and produces thinking, critical and capable of contributing to the development of their homeland. Disobedience to educational regulations has generated unsatisfactory results and increased concern for the pursuit of educational quality. We used a bibliographic research with a qualitative approach and based on some theorists and some official sources.

Keywords: Citizenship. Education. Educational system. Society.

\footnotetext{
${ }^{1}$ Mestre em Ciências da Educação pela Absoulute Christian University, pós- graduado em Supervisão Escolar pela Faculdade de Teologia Hokemãh - FATEH e Graduado em Normal Superior pela Universidade Estadual do Piauí - UESPI - E-mail: majebazori@hotmail.com.
} 


\section{INTRODUÇÃO}

Ao fazer-se menção à educação, vem em mente à prática dos bons costumes, do respeito, da tolerância, dos bons princípios, dos valores, do desmascaramento, do cumprimento da cidadania etc., ao tempo em que se questiona: “A educação que temos é a que, realmente, precisamos? A família e a escola estão educando de acordo com as normativas constitucionais?" Alinhando-se a LUFT (2005, p. 304), educação é o desenvolvimento integral e harmônico de todas as faculdades humanas e segundo a Constituição Federal (1988, art. 205), [...] ela visa ao pleno desenvolvimento da pessoa, seu prepara para o exercício da cidadania e sua qualificação para o trabalho.

É inegável que o sistema educacional brasileiro tenha avançado bastante, nas últimas décadas, no entanto vem deixando muito a desejar. Pode até estar preparando as crianças e os jovens para o mercado de trabalho, mas talvez não esteja preparando-os para o exercício da cidadania, para os desafios da vida. É notório que o avanço, nos mais diversos cursos, tem se intensificado em todo o território brasileiro. $O$ número de diplomados, com extraordinários conhecimentos científicos, tem se intensificado, no entanto o número de analfabetos funcionais ainda é, absolutamente, assustador.

As nossas escolas preocupam-se em seguir as orientações exigidas pelo sistema, mas descuidam-se, muitas vezes, em complementar a educação para à vida. O sistema educacional visa diplomas e a preparação para o mercado de trabalho. A sociedade postula por uma educação onde o indivíduo reconheça-se como ser importante e imprescindível na construção social.

A sociedade necessita de uma educação libertadora e propiciadora de luzes psicológicas, capazes de diluir, ou pelo menos atenuar, a alienação e o analfabetismo funcional. Uma educação que incentive novos pensadores capazes de criar, de produzir e, principalmente, de organizar seus pensamentos e planejar o futuro. Uma educação que reconheça o indivíduo como ser importante da sociedade, quando previamente preparado, capaz de contribuir para o crescimento e desenvolvimento do país. Uma nação só terá condições de desenvolver-se quando a educação for tratada seriamente e considerada como 
prioridade. Como dizia FREIRE (200o): "Se a educação sozinha não transforma a sociedade, sem ela tampouco a sociedade muda."

Analogicamente, como uma plantinha que para crescer ereta e se tornar frondosa, capaz de oferecer sombra e produzir frutos além de outros bens, assim também é o ser humano que necessita de cuidados e orientações constantes para uma boa formação, tanto física quanto psicológica. Aliás, tudo aquilo que for trabalhado com amor, carinho e dedicação tende a tornar-se algo interessante. As qualidades almejadas e adquiridas por um indivíduo, são consequências de extraordinárias ações realizadas no passado. Uma educação mal trabalhada resultará na produção de indivíduos mascarados, alienados e incapazes de exercer a sua cidadania diante dos desafios com que a vida se depara.

\section{O RAIO X DA EDUCAÇÃO BRASILEIRA}

Apesar de alguns avanços, na área educacional, nosso país ainda apresenta um número bastante preocupante de analfabetos, pois segundo o IBGE (2019), o mesmo possui II,3 milhões de pessoas acima de I5 anos de idade não sabem ler nem escrever, ou seja, 6,8\% de sua população.

A educação brasileira apresenta uma gama de carências na formação educacional. Muitas pessoas desconhecem os princípios básicos exigidos pela educação. Exigem demais dos outros e fazem de menos, quando o fazem, de si mesmos. São excelentes para requererem o que precisam por direito, mas retardam nos cumprimentos do que tem que ser feito. $\mathrm{O}$ individualismo e o egocentrismo tem falado mais alto, criando espaços para a ignorância e a vulgaridade. Parece até que as palavrinhas mágicas, que deveriam fazer parte do seu vocabulário, entraram em extinção.

Não é difícil encontrar pessoas eruditas e portadoras de alguns diplomas, desrespeitando as normativas educacionais e ignorando à prática dos bons costumes. Chegam a supervalorizarem-se, achando-se no direito de menosprezar o outrem, em algumas circunstâncias. Demonstram uma enorme dificuldade de relacionamento com outras pessoas, sobretudo com aquelas que pertencem a outros grupos e/ou níveis sociais. Desconhecem a humildade, ignoram a igualdade e apresentam imensurável ganância pelo poder e/ou status sociais. 
As facilidades educacionais, ofertadas na atualidade, poderão ser as principais responsáveis pelas dificuldades no futuro. É impossível educar com a ausência do respeito, da seriedade, do compromisso e da moralidade. Estamos precisando de uma educação que propicie o ajustamento de conduta do indivíduo na sociedade que ele faz parte, contribuindo, de certa forma, com o seu desenvolvimento sine qua non. A educação prevista nas fontes oficiais expressa uma formação qualitativa, onde o indivíduo passa a ser cidadão e, consequentemente, um grande aliado da sociedade. No entanto, o que se tem observado é a fomentação por amostragens estatísticas e numerológicas pelo Estado resultando, assim, em uma formação que não atende os requisitos propostos pela legislação vigente. Faltam refletores para esse campo tão sublime e imprescindível ao desenvolvimento de uma nação. A obscuridade no campo educacional vem ganhando fôlego, ao tempo em que se constrói uma sociedade vulnerável e desprovida de conhecimentos necessários a sua erudição.

\begin{tabular}{|c|c|}
\hline A EDUCAÇÃO QUE TEMOS & $\begin{array}{l}\text { A EDUCAÇÃO QUE A SOCIEDADE } \\
\text { PRECISA }\end{array}$ \\
\hline $\begin{array}{l}\text { - Ensina o que o sistema exige. } \\
\text { - } \text { Ensina conteúdos inconvenientes } \\
\text { à realidade do aluno. } \\
\text { - O professor fala e o aluno, } \\
\text { simplesmente, ouve. } \\
\text { - O professor é, muitas vezes, } \\
\text { onisciente. } \\
\text { - A tarefa pedagógica é exclusiva } \\
\text { dos professores. } \\
\text { - Burla as leis, engrinalda às } \\
\text { estatísticas e camufla a realidade. } \\
\text { - O professor, muitas vezes, faz de } \\
\text { conta que ensina o aluno, comumente, } \\
\text { faz de conta que aprende. } \\
\text { - Apresenta grande fomentação } \\
\text { pelas estatísticas numerológicas de } \\
\text { dados. } \\
\text { - Considera a educação como plano } \\
\text { secundário. } \\
\text { - O professor não é respeitado, } \\
\text { tampouco, valorizado e reconhecido } \\
\text { socialmente. } \\
\text { - É fundamentada nos interesses } \\
\text { do capitalismo. }\end{array}$ & $\begin{array}{l}\text { - A que ensine o que os alunos precisam. } \\
\text { - A que prepare os alunos para o } \\
\text { enfrentamento os desafios da vida. } \\
\text { - Que professores dialoguem com os } \\
\text { alunos. } \\
\text { - A que o professor seja também um } \\
\text { aprendiz. } \\
\text { - Que o currículo pedagógico seja tarefa } \\
\text { coletiva. } \\
\text { - Que seja democrática, transparente e } \\
\text { comprometida com à sociedade. } \\
\text { - A que eduque com seriedade, } \\
\text { considerando a educação como principal } \\
\text { transformadora da sociedade. } \\
\text { - A que desenvolva estratégias para o } \\
\text { resgate da qualidade do ensino. } \\
\text { - Que considere a educação como } \\
\text { prioridade. } \\
\text { - A que o professor seja valorizado, } \\
\text { respeitado e reconhecido como o principal } \\
\text { articulador do ensino-aprendizagem. } \\
\text { - Que seja fundamentada nos interesses } \\
\text { da sociedade. } \\
\text { - A que os professores apostem em suas } \\
\text { capacidades de superação. }\end{array}$ \\
\hline
\end{tabular}


- Grande parte dos professores duvidam na capacidade dos alunos.

- Engatinha, patina e não consegue chegar onde devia.

- É produtora de um grande número de analfabetos funcionais.

- É incapaz de oferecer às condições necessárias para que $o$ indivíduo torne-se

um verdadeiro cidadão.
- Que desenvolva ações em busca de resultados que condigam com às normativas.

- Que produza cidadãos críticos e capazes de contribuir com o desenvolvimento social.

- Que tenha a funcionalidade específica de emancipadora da cidadania.

A sociedade brasileira conclama por uma educação desmacaradora e democrática, com condições de oferecer os suportes necessários para a superação dos desafios que a vida encontra cotidianamente. O conhecimento é a principal ferramenta humana que, além de viabilizar a liberdade, proporciona o desenvolvimento psicológico do indivíduo para o melhor desempenho na sociedade em que está inserido. As luzes do conhecimento tornaramse opacas, nas últimas décadas, deixando o processo educacional um pouco sombrio e propagador do analfabetismo funcional. Entende-se que a educação que a sociedade brasileira precisa está precisando passar por uma filtragem com o intuito de descartar o inútil e priorizar o essencial. $O$ resgate pela qualidade educacional exige esforços coletivos e as políticas públicas devem estar em consonância com às ideologias da sociedade.

É inadmissível que em plena era de globalização continue-se assistindo uma educação cerceada, maquiadora e produtora de indivíduos alienados. Comumente, grande parte, desconhecem os seus deveres e, principalmente, os direitos que lhes são assistidos pela Constituição Brasileira, tornando-se vítimas fáceis do sistema, pelo qual tornam-se, banalmente, persuadidos. Por ser, notoriamente, a educação a principal e exclusiva arma defensora da cidadania e propulsora da equidade social, carece ser repensada pelos que a fazem, com a criação de novas estratégias que possam nortear a formação que a sociedade precisa.

No decorrer do século XVIII, surgia na Europa, sobretudo na França, as ideias iluministas, conhecidas como "Século das Luzes" onde defendiam os princípios da liberdade individual, da igualdade e do respeito aos direitos do cidadão. Pensadores iluministas franceses, defendiam a capacidade de raciocinar contra as trevas da ignorância. Comungando com essas concepções, defende-se que haja o novo século das luzes e que 
respinguem na educação brasileira com o intuito de despertar nos indivíduos a construção de uma nova sociedade. É inadmissível que depois de tantas políticas construídas e direcionadas ao âmago da educação brasileira, continue-se com essa opacificação social.

\section{O VERDADEIRO PAPEL DA FAMÍLIA NA CONSTRUÇÃO DA EDUCAÇÃO}

Percebe-se, com o passar dos anos, que muitas famílias não têm cumprido com o seu verdadeiro papel educacional, tampouco demonstrado preocupação com a formação familiar, com o seu desenvolvimento e com a sua interação social. Resultado de uma procriação aleatória e isenta de qualquer planejamento.

A educação é fruto berçal, papel íntegro e exclusivo da família, construído dia-apósdia. É na família que o indivíduo deve receber as primeiras instruções educacionais básicas. O que deve e o que não deve ser feito. O que é permitido é o que é proibido. Por ser a família o primeiro grupo social que o indivíduo participa, cabe-lhe, por dever, instruí-lo a comportarse socialmente, considerando a imprescimbilidade da empatia, em algumas circunstâncias.

Assim como a escola está incumbida em oferecer o que a sociedade realmente necessita, a família também deve ofertar aos filhos exatamente o que estão precisando e não o que eles querem. Para Mário Cortella, em entrevista à Rádio FM Catve, em Cascavel - PR (2016),

A tarefa de educação dos filhos é da família, em primeiro lugar, e do poder público,
de forma secundária. A escola faz à escolarização. Por isso, se a família não cumpre
aquilo que ela precisa cumprir, a escola não dará conta. A escola deve fazer uma
parceria com as famílias de modo também à formar os pais, tendo em vista que
uma parcela dos pais está perdida e vive uma situação de submissão com os filhos
(CORTELLA, 2016).

Diante do exposto, comunga-se com a concepção do escritor, uma vez que é notório o esquivamento de muitas famílias do dever de educar, cedendo tal tarefa à escola e sobrecarregando os seus profissionais que ao fazerem a escolarização precisam, ainda, complementar à educação. É a família que deve, a priori, orientar os seus filhos à viver socialmente, zelando pelo ambiente em que vivem ou onde quer que estejam. Se a família não corrigir o filho que jogou o papel da balinha ou o copinho de sorvete no chão, certamente ele continuará jogando o lixo em qualquer lugar, inclusive nos espaços públicos. Se os pais não se preocupam em dar bons exemplos de convivência pacífica no seio do lar, como poderia os filhos comportarem-se bem na sociedade? 
A família deve preocupar-se em acompanhar o desenvolvimento e a desenvoltura dos filhos tal qual o jardineiro acompanha o desenvolvimento de uma plantinha. Pelo contrário poderia ocorrer uma avaria, gerando consequências desagradáveis e talvez irreversíveis. Alguns pais pensam que dizer um "não" ao filho poderia machucá-lo quando, na verdade, expressam um "sim" agora sem se atentar que no futuro o machucão pode ser maior. $\mathrm{Na}$ concepção de Pepe Mujica, ex-presidente uruguaio,

\footnotetext{
Não devemos esperar que professores consertem as falhas na educação dos filhos. Em casa se aprende a cumprimentar, falar obrigado, ser limpo, ser honesto, ser correto, ser pontual, falar bem, não xingar, respeitar os semelhantes, ser solidário, mastigar com a boca fechada, não roubar, não mentir, cuidar das próprias coisas e das coisas dos outros e ser organizado. $\mathrm{Na}$ escola se aprende matemática, português, ciências, geografia inglês, geometria e é onde são reforçados os valores que os pais ensinam aos seus filhos (MUJICA, 2016).
}

Nas palavras do ex-presidente uruguaio, resume-se uma parte da verdadeira tarefa educacional cabível aos pais. A família precisa entender que por ser ela o primeiro grupo social em que o filho participa, cabe-lhe à incumbência de oferecer as primeiras lições educacionais. Assim, ao chegar à escola, segundo grupo social, o indivíduo receberá a escolarização científica, além da complementação educacional que tenha, supostamente, faltado em casa. Geralmente, famílias psicologicamente estruturadas e que adotam a educação como cultura, tornam-se grandes parceiras do processo educacional, proporcionando uma relação recíproca entre os segmentos e consolidando uma formação qualitativa aos seus filhos.

\section{O DESCUMPRIMENTO DAS NORMATIVAS EDUCACIONAIS E SEUS EFEITOS NEGATIVOS}

Nosso país tem apresentado muitas políticas públicas direcionadas ao sistema educacional, através da elaboração e/ou implementação de diretrizes que visam o melhoramento do setor educacional e a transformação da sociedade. Contudo, muitas garantias expressas nos parágrafos, incisos, alíneas e artigos dessas leis são ignoradas, quer dizer, não são cumpridas. A exemplo das seguintes metas do Plano Nacional de Educação $\mathrm{PNE}$ /2014:

a) Meta o6 oferecer educação em tempo integral em, no mínimo, 50\% das escolas públicas, até 2024 ; 
b) Meta o7 fomentar a qualidade da educação básica em todas as etapas e modalidades, com melhoria do fluxo escolar e da aprendizagem de modo a atingir as seguintes médias nacionais para o Ideb: Anos Iniciais do Ensino Fundamental 2019 = 5,7; Anos Finais do Ensino Fundamental 2019 = 5,2 e Ensino Médio 2019 = 5,0 (PNE, 2014).

Quando não se cumpre o que se planejou os resultados aparecerão aquém das expectativas, além de comprometer o andamento do processo. Analogicamente falando, é como estar doente, passar pelo médico, ignorar a receita e comprar qualquer remédio. A pesar do planejamento ser flexível, ou seja, sujeito à mudanças ou ajustes, precisa estar em consonância com a prática para a obtenção de melhores resultados. Os gráficos abaixo explicitam resultados que não estão de acordo com as normativas supracitadas.

Tabela or

\section{PERCENTUAL DE MATRÍCULAS EM TEMPO INTEGRAL NO ENSINO FUNDAMENTAL POR ETAPA DE ENSINO E REDE - 2015-2019}

\begin{tabular}{|c|c|c|c|c|c|c|}
\hline \multirow{2}{*}{ ANO } & \multicolumn{6}{|c|}{ DEPENDENCIA ADMINISTRATIVA } \\
\cline { 2 - 7 } & \multicolumn{3}{|c|}{ Ensino fundamental } & \multicolumn{3}{c|}{ Ensino médio } \\
\cline { 2 - 7 } & Total & Pública & Privada & Total & Pública & Privada \\
\hline 2015 & $16,7 \%$ & $19,4 \%$ & $2,5 \%$ & $5,9 \%$ & $6,3 \%$ & $3,5 \%$ \\
\hline 2016 & $9,1 \%$ & $10,5 \%$ & $2,0 \%$ & $6,4 \%$ & $6,7 \%$ & $3,8 \%$ \\
\hline 2017 & $13,9 \%$ & $16,3 \%$ & $2,1 \%$ & $7,9 \%$ & $8,4 \%$ & $3,9 \%$ \\
\hline 2018 & $9,4 \%$ & $10,9 \%$ & $2,2 \%$ & $9,5 \%$ & $10,3 \%$ & $4,0 \%$ \\
\hline 2019 & $9,4 \%$ & $10,9 \%$ & $2,5 \%$ & $10,8 \%$ & $11,7 \%$ & $4,8 \%$ \\
\hline
\end{tabular}

Fonte: Elaboração própria com base nos dados do Censo da Educação Básica.

\section{IDEB - Resultados e Metas}

IDEB 2005, 2007, 2009, 2011, 2013, 2015, 2017, 2019 e Projeções para o BRASIL

Tabela $02 \quad$ Anos Iniciais do Ensino Fundamental

\begin{tabular}{|c|c|c|c|c|c|c|c|c|c|c|c|c|c|c|c|c|}
\hline & \multicolumn{8}{|c|}{ IDEB Observado } & \multicolumn{8}{|c|}{ Metas } \\
\hline & 2005 & 2007 & 2009 & 2011 & 2013 & 2015 & 2017 & 2019 & 2007 & 2009 & 2011 & 2013 & 2015 & 2017 & 2019 & 2021 \\
\hline Total & 3.8 & 4.2 & 4.6 & 5.0 & 5.2 & 5.5 & 5.8 & 5.9 & 3.9 & 4.2 & 4.6 & 4.9 & 5.2 & 5.5 & 5.7 & 6.0 \\
\hline
\end{tabular}




\begin{tabular}{|c|c|c|c|c|c|c|c|c|c|c|c|c|c|c|c|c|}
\hline Estadual & $3 \cdot 9$ & $4 \cdot 3$ & 4.9 & 5.1 & 5.4 & 5.8 & 6.0 & 6.1 & 4.0 & $4 \cdot 3$ & $4 \cdot 7$ & 5.0 & 5.3 & 5.6 & 5.9 & 6.1 \\
\hline Municipal & 3.4 & 4.0 & $4 \cdot 4$ & $4 \cdot 7$ & 4.9 & 5.3 & 5.6 & 5.7 & 3.5 & 3.8 & 4.2 & $4 \cdot 5$ & 4.8 & 5.1 & $5 \cdot 4$ & 5.7 \\
\hline Privada & 5.9 & 6.0 & 6.4 & 6.5 & 6.7 & 6.8 & $7 \cdot \mathrm{I}$ & 7.1 & 6.0 & 6.3 & 6.6 & 6.8 & 7.0 & 7.2 & 7.4 & 7.5 \\
\hline Pública & 3.6 & 4.0 & 4.4 & 4.7 & 4.9 & 5.3 & 5.5 & 5.7 & 3.6 & 4.0 & 4.4 & 4.7 & 5.0 & 5.2 & 5.5 & 5.8 \\
\hline
\end{tabular}

Fonte: Saeb e Censo Escolar

Tabela 03

Anos Finais do Ensino Fundamental

\begin{tabular}{|c|c|c|c|c|c|c|c|c|c|c|c|c|c|c|c|c|}
\hline & \multicolumn{8}{|c|}{ IDEB Observado } & \multicolumn{8}{|c|}{ Metas } \\
\hline & 2005 & 2007 & 200 & 201 & 2013 & 2015 & 2017 & 2019 & 2007 & 2009 & 2011 & 2013 & 2015 & 2017 & 2019 & 2021 \\
\hline Total & 3.5 & 3.8 & 4.0 & 4.1 & 4.2 & 4.5 & 4.7 & 4.9 & 3.5 & 3.7 & 3.9 & 4.4 & 4.7 & 5.0 & 5.2 & 5.5 \\
\hline \multicolumn{17}{|c|}{ Dependência Administrativa } \\
\hline Estadual & $3 \cdot 3$ & 3.6 & 3.8 & 3.9 & 4.0 & 4.2 & 4.5 & $4 \cdot 7$ & $3 \cdot 3$ & 3.5 & 3.8 & 4.2 & 4.5 & 4.8 & 5.1 & 5.3 \\
\hline $\begin{array}{l}\text { Municipa } \\
1\end{array}$ & 3.1 & 3.4 & 3.6 & 3.8 & 3.8 & 4.I & 4.3 & 4.5 & 3.1 & 3.3 & 3.5 & 3.9 & 4.3 & 4.6 & 4.9 & 5.I \\
\hline Privada & 5.8 & 5.8 & 5.9 & 6.0 & 5.9 & 6.1 & 6.4 & 6.4 & 5.8 & 6.0 & 6.2 & 6.5 & 6.8 & 7.0 & 7.1 & 7.3 \\
\hline Pública & 3.2 & 3.5 & 3.7 & 3.9 & 4.0 & 4.2 & 4.4 & 4.6 & 3.3 & 3.4 & 3.7 & 4.I & 4.5 & 4.7 & 5.0 & 5.2 \\
\hline
\end{tabular}

Fonte: Saeb e Censo Escolar

Tabela 04

\section{Ensino Médio}

\begin{tabular}{|c|c|c|c|c|c|c|c|c|c|c|c|c|c|c|c|c|}
\hline & \multicolumn{8}{|c|}{ IDEB Observado } & \multicolumn{8}{|c|}{ Metas } \\
\hline & 2005 & 2007 & 2009 & 201 & 2013 & 2015 & 2017 & 2019 & 2007 & 2009 & 2011 & 2013 & 2015 & 2017 & 2019 & 2021 \\
\hline Total & 3.4 & 3.5 & 3.6 & 3.7 & 3.7 & 3.7 & 3.8 & 4.2 & 3.4 & 3.5 & 3.7 & 3.9 & 4.3 & 4.7 & 5.0 & 5.2 \\
\hline \multicolumn{17}{|c|}{ Dependência Administrativa } \\
\hline Estadual & 3.0 & 3.2 & 3.4 & 3.4 & 3.4 & 3.5 & 3.5 & 3.9 & 3.1 & 3.2 & 3.3 & 3.6 & 3.9 & 4.4 & 4.6 & 4.9 \\
\hline Privada & 5.6 & 5.6 & 5.6 & 5.7 & 5.4 & 5.3 & 5.8 & 6.0 & 5.6 & 5.7 & 5.8 & 6.0 & 6.3 & 6.7 & 6.8 & 7.0 \\
\hline Pública & 3.1 & 3.2 & 3.4 & 3.4 & 3.4 & 3.5 & 3.5 & 3.9 & 3.1 & 3.2 & 3.4 & 3.6 & 4.0 & 4.4 & 4.7 & 4.9 \\
\hline
\end{tabular}

Fonte: Saeb e Censo Escolar.

Os resultados marcados em verde referem-se ao Ideb que atingiu a meta.

No entanto, o I o demonstrativo aponta que em 2019 a educação havia atingido apenas 9,4\% de tempo integral, no Ensino Fundamental e 10,8\% no Ensino Médio, perfazendo um total de $20,2 \%$. E no $2^{2}$ - demonstrativo do mesmo ano, observa-se que apenas os Anos Iniciais 
do Ensino Fundamental atingiram a meta prevista, 5,9 ao invés de 5,7; ficando as outras etapas com déficit, a saber: Anos Finais do Ensino Fundamental com 4,9 quando a expectativa era de 5,2 e no Ensino Médio com 4,2 quando se projetava 5,0.

Evidencia-se, portanto, que não basta planejar bem. A fidelidade ao planejamento de um processo é que propiciará o produto almejado. Quando se abandona o mapa e/ou a bússola que norteia o destino, passa-se a viajar aleatoriamente com o acompanhamento de muitas incertezas.

\section{CONSIDERAÇÕES FINAIS}

Com efeito, existe uma grande discrepância entre a educação que temos e a que a sociedade precisa, a que se está expressa nas normativas das fontes oficiais e a que realmente se faz. De modo, que educação hodierna não está corroborando, eficazmente, com a construção da autêntica cidadania prevista na Constituição Federal, deixando lacunas para a construção de uma sociedade vulnerável, passiva e mascarada.

O país que zela pela sua nação é aquele que investe, sem economizar, na educação,

delineando caminhos e construindo os pilares da cidadania que a sociedade precisa. A qualidade da educação tende a favorecer a liberdade, a atenuar a corrupção e propiciar a busca contínua por uma sociedade mais justa. Que educação é essa, em que grande parte das pessoas desconhecem os princípios básicos para a vida como a moral, a ética, o caráter e a honestidade, fundamentais para a convivência social? Que educação é essa cuja população brasileira apresenta II,3 milhões de analfabetos?

É sabido que uma nação constituída por indivíduos devidamente instruídos tende a desenvolver-se ininterruptamente, ao tempo em que os mesmos apresentam-se a postos para conduzir, com responsabilidade o seu país. Investir bem na educação é, ao mesmo tempo, otimizar um processo responsável pelo acendimento das luzes nas mentes humanas, com o intuito de atenuar os erros e avançar nos acertos.

Com embasamento nas palavras de Freire, conclui-se que a sociedade brasileira tende a mudar a partir do momento em que o Estado considerar a educação como principal responsável pela mudança social de seu povo. Quando se qualifica a educação de uma nação, estimula-se, ao mesmo tempo, a sua civilidade, com a certeza de menos problemas e de maiores chances de desenvolvimento. Uma sociedade civilizada é aquela que possui senso 
crítico, com capacidade de dialogar e de sugerir estratégias para o desenvolvimento de seu país; uma sociedade alienada, simplesmente concorda e absorve tudo aquilo que lhe é oferecido.

\section{REFERÊNCIAS}

BRASIL, Constituição da República Federativa do Brasil, 1988.

BRASIL, Instituto Brasileiro de Geografia e Estatística - IBGE, 2019.

BRASIL, Instituto Nacional de Estudos e Pesquisas Educacionais Anísio Teixeira - INEP, 2019.

BRASIL, Plano Nacional de Educação - PNE. Lei no 13.005, de 25 de junho de 2014.

CORDANO, José Alberto Mujica. Pequenos Grandes Valores da Educação. https://www.diariopopular.com.br/opinião/pequenos-grandes-valores-da educaçãoI10868/2016.

CORTEllA, Mário Sérgio. Educação x Escolarização - Entrevista à Rádio FM-91,7Cascavel - PR. 28/10/2016.

FREIRE, Paulo Reglus Neves, I921-1997. Pedagogia da indignação: cartas pedagógicas e outros escritos/Paulo Freire. - São Paulo: Editora UNESP, 2000.

LUFT, Celso Pedro. Minidicionário Luft/ Celso Pedro Luft. Colaboradores: Francisco de Assis Barbosa, Manuel da Cunha Pereira. Organização e Supervisão: Lya Luft - 2ı ed. - São Paulo: Ática, 2005.

SCHMIDT, Mário Furley. Nova História Crítica - Mário Furley Schmidt. 2 ${ }^{\underline{a}}$ ed. e atual. São Paulo: Nova Geração, 2002. 